УДК 378.14

\title{
В.В. Новокрещенов, С.А. Алабужев
}

\section{О ТРЕБОВАНИЯХ К ПОДГОТОВКЕ КАДРОВ ПО ФИЗИЧЕСКОЙ КУЛЬТУРЕ И СПОРТУ В УДМУРТСКОЙ РЕСПУБЛИКЕ}

Рассматривается ситуация с кадровым обеспечением отрасли «Физическая культура и спорт» в Удмуртской Республике за последние 5 лет по данным государственной статистической отчетности и в связи с этим процесс подготовки кадров в рамках направления 49.00.00 «Физическая культура и спорт» в Удмуртской республике в целом и в Удмуртском государственном университете в частности. С помощью платформы ресурса Google Forms проведен опрос 80 организаций работодателей с целью формирования в университете системы, обеспечивающей подготовку квалифицированных кадров по физической культуре и спорту. По мнению работодателей, система должна включать: выполнение требований ФГОС направления 49.03.01 «Физическая культура», требований профессиональных стандартов в области физической культуры и спорта; рейтинг компетенций; практико-ориентированный подход к обучению в процессе организации практик и изучения спортивно-педагогических дисциплин. Кроме того, в статье систематизированы и обобщены предложения по форматированию работы с абитуриентами и выпускниками для закрепления кадров в физкультурно-спортивных организациях республики.

Ключевые слова: образовательная система, подготовка кадров, физическая культура и спорт, требования работодателей, федеральный стандарт, профессиональный стандарт, компетенции выпускников.

DOI: $10.35634 / 2412-9550-2020-30-4-407-420$

Введение. Подготовка специалистов для отрасли «Физическая культура и спорт» в системе высшего профессионального образования Российской Федерации осуществляется в рамках направления 49.00.00 «Физическая культура и спорт». На уровне подготовки бакалавров в 2017-2019 годах вступили в силу четыре ФГОС ВО (3++): 49.03.01 «Физическая культура»; 49.03 .02 «Физическая культура для лиц с отклонениями в состоянии здоровья»; 49.03 .03 «Рекреация и спортивнооздоровительный туризм»; 49.03 .04 «Спорт» [12]. Подготовку кадров в РФ для отрасли осуществляют в основном организации высшего образования, находящиеся в ведомственном подчинении Министерства спорта России, из них: университетов физической культуры и спорта - 5, академий - 6, институтов - 3, филиалов спортивных вузов - 13. В спортивных вузах страны обучается более 36 тыс. студентов, контрольные цифры приема абитуриентов по направлению «Физическая культура» за счет средств федерального бюджета выделяются преимущественно в отраслевые спортивные вузы (ежегодно от 5,5 до 6,0 тыс.) [9]. В этой связи конкурировать на рынке физкультурного образования Приволжского федерального округа вузам Удмуртской Республики, где такого профильного спортивного вуза нет, сложно, так как они есть в соседних регионах: в Пермском крае - Чайковский институт ФКиС (прием абитуриентов за счет финансирования из средств федерального бюджета в текущем году по всем формам обучения и уровням образования - 200 мест, в том числе, бакалавров - 154) [6], в республике Татарстан - Поволжская академия ФКиС (число бюджетных мест на 2020/2021 учебный год еще больше - 520) [5]. В Удмуртской Республике подготовку кадров для отрасли физической культуры и спорта осуществляют образовательные организации среднего и высшего профессионального образования широкого профиля. Так, программы среднего профессионального образования по укрупненной группе специальностей (УГС) 49.00.00 «Физическая культура и спорт» реализуют в Ярском политехникуме, Удмуртском республиканском социально-педагогическом колледже (г. Ижевск), Можгинском педагогическом колледже им. Т.К. Борисова, Сарапульском педагогическом колледже. Учреждения СПО готовят специалистов с присвоением квалификации «учитель физической культуры» и педагог физической культуры в основном за счет средств регионального бюджета. Ежегодный выпуск специалистов со средним профессиональным образованием для сферы образования, физической культуры и спорта республики составляет около 100 человек. Специалистов с высшим образованием вот уже более 70 лет готовит Удмуртский государственный университет, в структуре которого на базе факультета создан Институт физической культуры и спорта (далее - ИФКиС УдГУ). При этом следует отметить, что выделение бюджетных мест Министерством науки и высшего образования РФ для приема студентов происходит не стабильно и преимущественно по направлению «Педагогическое образование», т. е. для подготовки учителей физической культуры, а не 
тренеров по спорту, как того требуют в настоящее время федеральные стандарты спортивной подготовки (далее - ФССП). Удмуртский государственный университет в настоящее время реализует только один ФГОС ВО направления 49.00.00: 49.03 .01 «Физическая культура» (бакалавриат). Основная причина - небольшое количество бюджетных мест, выделяемых министерством (например, на прием абитуриентов за счет средств федерального бюджета в 2020 году выделено всего 22 места) [14]. Надо отметить, что в ГГПИ (г. Глазов) также с 2011 года готовят бакалавров для образовательной отрасли по очной и заочной форме обучения, реализуют профессиональную переподготовку. Например, в 2020 году набор по бюджету на очное обучение составил 3 академические группы по 20 человек направления 44.03.02 «Психолого-педагогическое образование». Профиль «Психология и педагогика физического воспитания и спорта». 44.03.05 «Педагогическое образование» с двумя профилями подготовки. Профили: «Физическая культура» и «Спортивная подготовка». Поскольку данные направления относятся к подготовке кадров для отрасли образования, они не стали предметом данного исследования.

С учетом изложенного, когда в соседних регионах имеются такие конкурентные преимущества для поступающих, Удмуртский университет должен работать с выпускниками спортивных и общеобразовательных школ, тренерами, спортсменами на опережение, предоставляя для них еще в период обучения в школе максимально подробную информацию об условиях обучения, образовательных программах, работодателях, делая акцент на практико-ориентированное обучение и максимальное взаимодействие с организациями-работодателями до и во время учебы, прохождения практик. Важным конкурентным преимуществом для регионального вуза в подготовке кадров становится учет конкретных требований и условий к региональным особенностям развития отрасли и организацийработодателей к овладению выпускниками наиболее востребованными компетенциями, предусмотренными ФГОС ВО в аспекте требований профессиональных стандартов (ПС) и ФССП в области физической культуры и спорта.

В этой связи целью работы стало формирование в УдГУ образовательной системы, обеспечивающей подготовку квалифицированных кадров для сферы «Физическая культура и спорт», способной в среднесрочной перспективе обеспечить необходимым количеством выпускников, компетенции которых отвечают актуальным потребностям рынка труда физкультурно-спортивных и образовательных организаций Удмуртской Республики.

Методы и организация исследования. Характеристика рынка труда для выпускников ИФКиС Удмуртского университета осуществлялась на основе данных анализа государственной статистической отчетности за последние 5 лет (2015-2019 годы; формы 1-ФК, 5-ФК, 3-АФК) [11] официально запрошенных в Министерстве по физической культуре, спорту и молодежной политике УР. Для выявления требований организаций-работодателей к подготовке выпускников Удмуртского государственного университета по направлению 49.03.01 «Физическая культура» среди организаций - работодателей, задействованных в области физической культуры и спорта, а также образования, было проведено анкетирование в срок с 25 мая по 15 июня 2020 года. Анкетирование прошло с использованием pecypca Google Forms, что позволило оперативно следить за результатами и облегчило анализ итоговых данных [1]. Ссылка на анкету по предварительной договоренности была направлена физкультурно-спортивным организациям на территории Удмуртской Республики. В итоге опрошено 80 организаций-работодателей, в том числе: руководители спортивных школ и школ олимпийского резерва Удмуртской Республики - 17, детско-юношеских спортивных школ - 12, общеобразовательных школ - 16 , органов управления физической культурой и спортом и руководителей спортивных сооружений - 6, представителей фитнес-индустрии - 8, региональных отделений спортивных федераций по видам спорта - 11. По виду собственности организации-респонденты распределились следующим образом: государственные - 18,6 \%; муниципальные - 75,7 \%, остальные - общественные и частные.

Результаты исследования и их обсуждение. Характеризуя рынок труда для выпускников ИФКиС УдГУ нашей республики, следует отметить, что до недавнего времени (до 2015 г.) [17] практически все детские спортивные школы Удмуртской Республики были отнесены к отрасли образования и осуществляли учебно-тренировочный процесс с получением лицензии на образовательную деятельность как учреждения дополнительного образования детей спортивной направленности. Позднее были внесены изменения и дополнения в Ф3 № 329 «О физической культуре и спорте» в части утверждения - ФССП «как совокупности минимальных требований к спортивной подготовке по видам спорта, разработанных и утвержденных в соответствии с настоящим законом и обязательных для организаций осуществляющих спортивную подготовку» [17]. По этой причине в регионах началась по- 
степенная передача ДЮСШ из системы управления образованием в систему управления спортом. Хотя надо отметить, что п. 6. статьи 33 закона устанавливает, что спортивную подготовку могут также реализовать образовательные организации дополнительного образования детей, осуществляющие деятельность в области физической культуры и спорта и находящиеся в том числе и в ведении органов управления образованием [17]. Вместе с тем в результате реорганизации на первом этапе реформы в ведомственное подчинение спортивного ведомства (в том числе на уровне муниципалитетов) из системы образования были переданы спортивные школы городов: Ижевска, Воткинска, Глазова, Сарапула, Можги. В подчинении органов управления образованием остались ДЮСШ сельских районов Удмуртской Республики, как учреждения дополнительного образования детей спортивной направленности, а также АОУДО УР «Республиканская специализированная детско-юношеская спортивная школа» (РСДЮСШ) Министерства образования и науки Удмуртской Республики, выполняющая функции методического центра. В итоге по состоянию на 01.01.2020 г. система спортивной подготовки в Удмуртской Республике, реализуемая на основе ФССП, охватывает 1 центр спортивной подготовки сборных команд республики, 12 школ олимпийского резерва, 24 спортивных центра, а также 33 ДЮСШ сельских районов, в которых работает более 1300 тренеров и около 1500 административных работников и методистов, требующих постоянного кадрового обновления, профессиональной подготовки и переподготовки. Кроме того, как уже было отмечено выше, 25 муниципальных детскоюношеских спортивных школ и 1 республиканская СДЮСШ до настоящего времени функционируют в системе образования Удмуртской Республики как учреждения дополнительного образования детей спортивной направленности. Все названные организации финансируются из республиканского или муниципальных бюджетов Удмуртской Республики. Таким образом, в целом система спортивной подготовки и дополнительного образования детей охватывает более 90 организаций-работодателей, и, по результатам анализа государственной статистической отчетности (форма № 1-ФК), в ней было занято на конец 2019 года более 4000 специалистов (рис. 1).

\section{Специалистов в УР по ФКиС (чел.)}

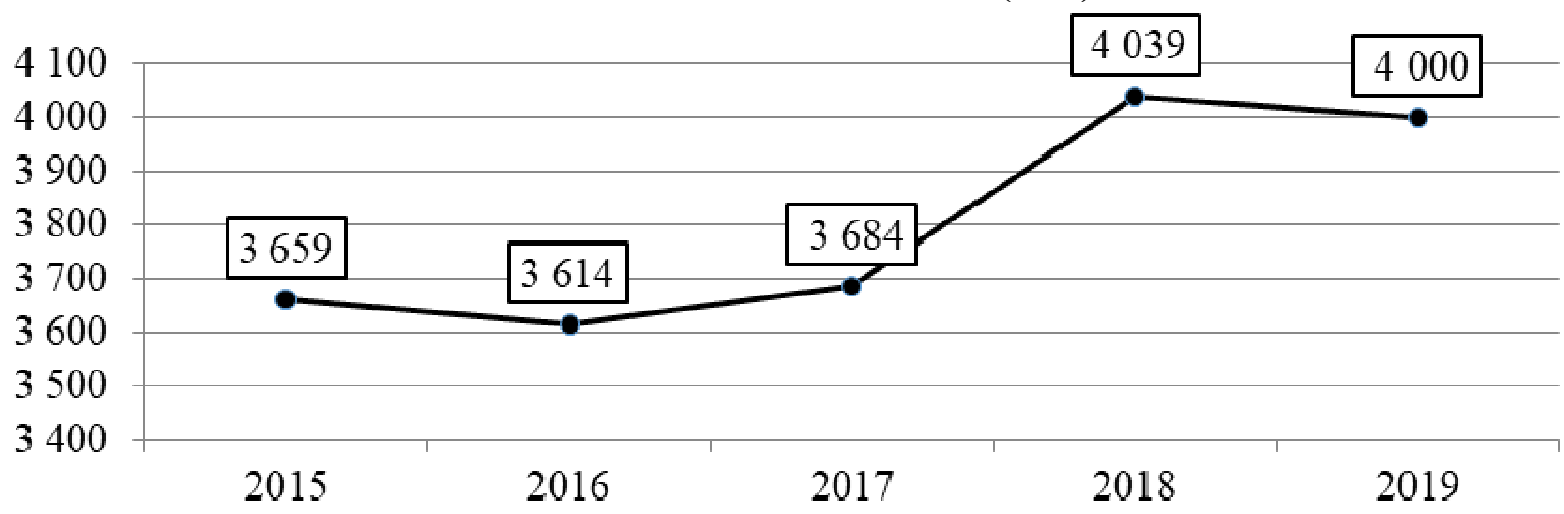

Рис. 1. Динамика количества специалистов физкультурно-спортивной отрасли в Удмуртской Республике за 2015-2019 годы

Анализ возраста физкультурно-спортивных работников в Удмуртской Республике (по данным статистического наблюдения 1-ФК) за последние пять лет показал снижение доли специалистов в возрасте до 30 лет на 10,2 \% и увеличение лиц старше 60 лет на 43,7 \%. То есть довольно быстрыми темпами происходит старение тренеров по спорту по причине отсутствия эффективных инструментов привлечения в отрасль молодых специалистов (рис. 2, 3). 


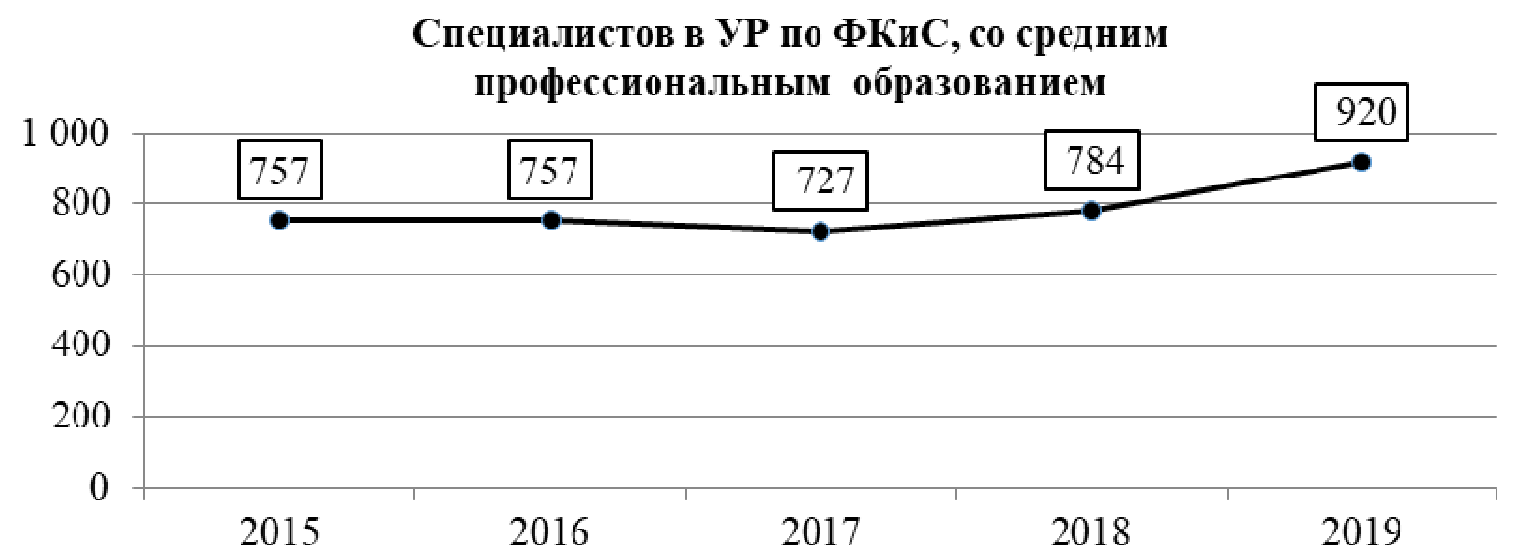

Рис. 2. Динамика численности специалистов по физической культуре и спорту в УР с СПО в 2015-2019 гг.

За последний год просматривается явная тенденция увеличения специалистов отрасли, имеющих среднее профессиональное образование (с 784 до 920 чел) на 17,4 \% и уменьшения числа специалистов с высшим образованием с 3011 до 2800 чел. (-7,1\%). Кризисное состояние отрасли отражает также и количество вакансий тренеров, которое держится на протяжении двух последних лет на одном уровне - 133 (рис. 4).

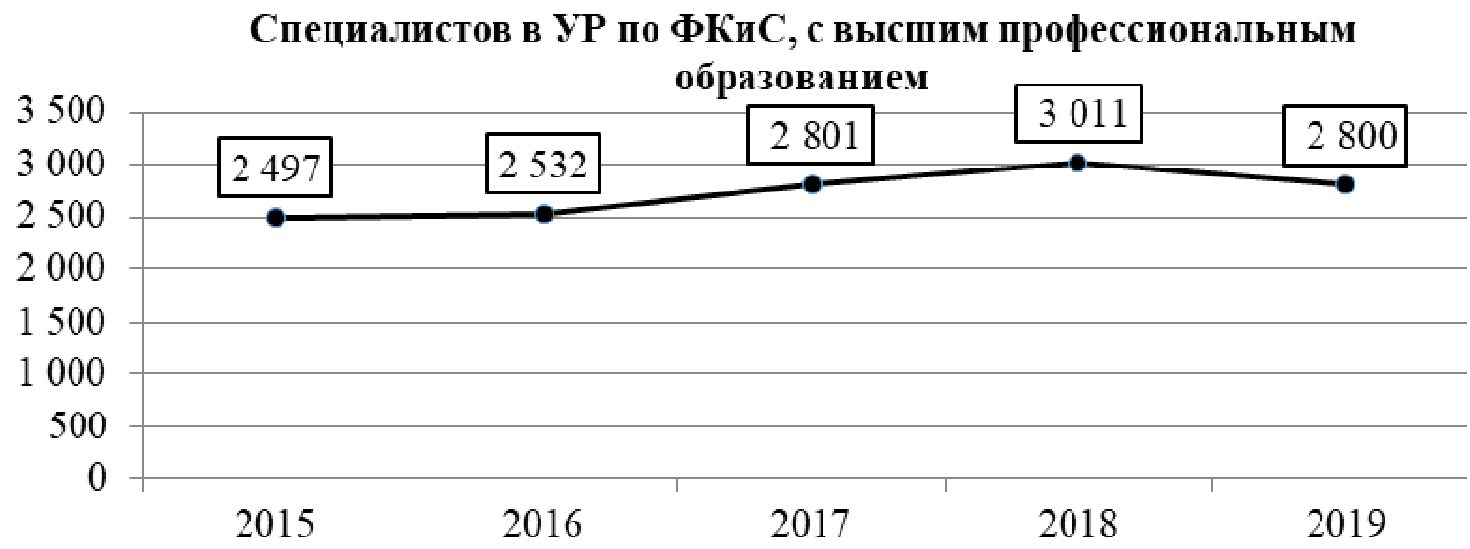

Рис. 3. Динамика численности специалистов по физической культуре и спорту в УР с ВО за период 2015-2019 годы

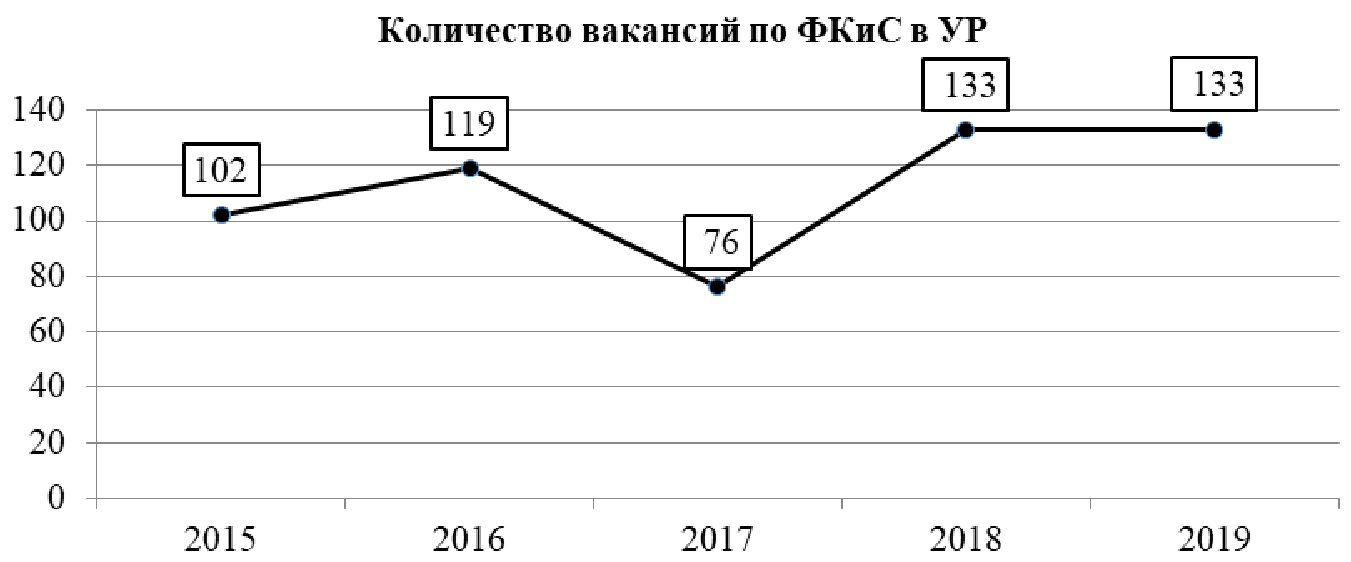

Рис. 4. Количество тренерских вакансий в физкультурно-спортивных организациях Удмуртской Республики в 2015-2019 гг. 
Тендениии развития отрасли. По прогнозу Министерства социальной политики и труда УР, специалистов по физической культуре и спорту в Удмуртии на ближайшие 5 лет (к 2026 году) в разрезе видов экономической деятельности (код ОКВЭД: раздел R. Деятельность в области культуры, спорта, организации досуга и развлечений) дополнительно потребуется 566 человек [13]. Рост к 2020 году составил всего 41 человек или 7,8 \% (табл. 1).

Таблица 1

Прогноз необходимого количества специалистов по физической культуре и спорту для УР по видам экономической деятельности

\begin{tabular}{|c|c|c|c|c|c|c|}
\hline $\begin{array}{c}2020 \text { г., } \\
\text { прогно3 }\end{array}$ & $\begin{array}{c}2021 \text { г., } \\
\text { прогно3 }\end{array}$ & $\begin{array}{c}2022 \text { г., } \\
\text { прогно3 }\end{array}$ & $\begin{array}{c}2023 \text { г., } \\
\text { прогно3 }\end{array}$ & $\begin{array}{c}2024 \text { г., } \\
\text { прогно3 }\end{array}$ & $\begin{array}{c}2025 \text { г., } \\
\text { прогно3 }\end{array}$ & $\begin{array}{c}2026 \text { г., } \\
\text { прогно3 }\end{array}$ \\
\hline 525 & 508 & 592 & 620 & 626 & 585 & 566 \\
\hline
\end{tabular}

Прогноз потребности рынка труда Удмуртской Республики в кадрах в разрезе укрупненных групп специальностей по всем уровням образования на 2020-2026 годы еще более неутешительный. Так, по укрупненной группе специальностей 49.00 .00 «Физическая культура и спорт» в УР будут востребованы дополнительно к имеющимся всего 73 специалиста, то есть роста в сопоставлении к 2020 г. практически не предполагается (табл. 2).

Таблица 2

Прогноз потребности рынка труда по укрупненной группе специальностей 49.00 .00 «Физическая культура и спорт» на период до 2026 года*

\begin{tabular}{|c|c|c|c|c|c|c|}
\hline $\begin{array}{c}2020 \text { г., } \\
\text { прогно3 }\end{array}$ & $\begin{array}{c}2021 \text { г., } \\
\text { прогно3 }\end{array}$ & $\begin{array}{c}2022 \text { г., } \\
\text { прогно3 }\end{array}$ & $\begin{array}{c}2023 \text { г., } \\
\text { прогно3 }\end{array}$ & $\begin{array}{c}2024 \text { г., } \\
\text { прогно3 }\end{array}$ & $\begin{array}{c}2025 \text { г., } \\
\text { прогно3 }\end{array}$ & $\begin{array}{c}2026 \text { г., } \\
\text { прогно3 }\end{array}$ \\
\hline 66 & 61 & 74 & 70 & 70 & 67 & 65 \\
\hline 73 & 70 & 82 & 78 & 79 & 75 & 73 \\
\hline
\end{tabular}

* Первая строка - специалисты среднего звена; вторая - специалисты с высшим образованием.

Требования организаций-работодателей к выпускникам УдГУ по направлению 49.03.01 "Физическая культура» по данным анкетного опроса.

Результаты анкетирования физкультурно-спортивных организаций республики показали, что среди специалистов по физической культуре и спорту всех уровней преобладают выпускники Удмуртского университета. Ответы на вопрос: «Выпускники каких образовательных организаций по специальности “Физическая культура и спорт” работают в вашей организации?» показали, что рынок физкультурного образования в Удмуртской Республике практически монопольно принадлежит Удмуртскому государственному университету, выпускники которого составили 64,7 \% работающих в отрасли специалистов (рис. 5).

Выпускники каких образовательных организаций по специальности “Физическая культура и спорт" работают в вашей организации?
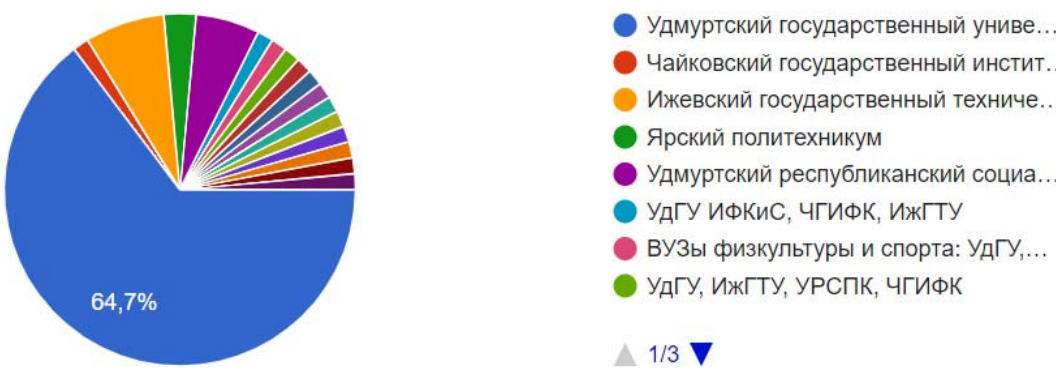

Рис. 5. Распределение специалистов по физической культуре и спорту УР в зависимости от места получения профессионального образования

При этом 88 \% опрошенных представителей работодателя отметили высокий уровень теоретической подготовленности выпускников института физической культуры и спорта УдГУ, в том числе $23,5 \%$ - удовлетворены полностью, 51,5 \% - в основном, 13,2 \% - частично (рис. 6 ). 
Насколько Ваша организация удовлетворена уровнем теоретической подготовки выпускников ИФКиС УдГУ?

68 ответов

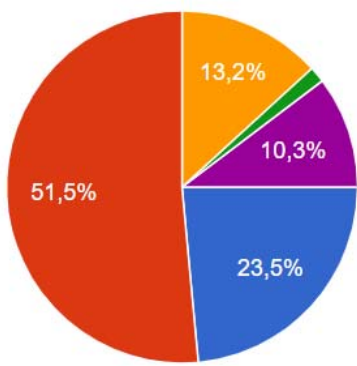

Полностью удовлетворень

В основном удовлетворены

Частично удовлетворень

Полностью не удовлетворень

Затрудняюсь ответить

Рис. 6. Удовлетворенность работодателей уровнем теоретической подготовленности выпускников УдГУ

Удовлетворенность работодателей практической подготовленностью выпускников ИФКиС еще выше: 89,9 \% опрошенных представителей работодателей отметили высокий уровень подготовленности к практической работе. В ответах на первый и второй вопросы затруднялись с ответом примерно $10 \%$ респондентов (рис. 7).
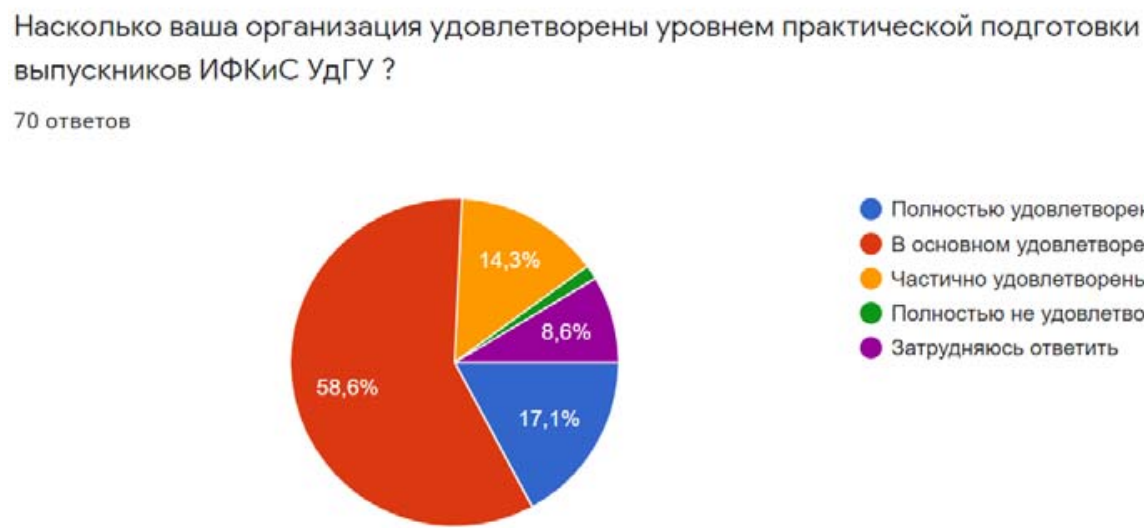

Полностью удовлетворены

В основном удовлетворень

Частично удовлетворены

Полностью не удовлетворень

Затрудняюсь ответить

Рис. 7. Удовлетворенность работодателей уровнем практической подготовленности выпускников ИФКиС УдГУ

Указывая на основные достоинства в подготовке выпускников УдГУ, респонденты сделали следующие выборы, в \% (табл. 3., выбор не более 4-х вариантов ответов).

Таблица 3

Достоинства выпускников института ФКиС УдГУ, отмеченные респондентами по результатам анкетирования $(\mathbf{n}=68)$

\begin{tabular}{|l|l|l|}
\hline № п/п & \multicolumn{1}{|c|}{ Достоинства } & Результаты, \% \\
\hline 1. & Соответствие профессиональному стандарту & 51,5 \\
\hline 2. & Желание работать & 48,5 \\
\hline 3. & Стремление к саморазвитию и самоорганизации & 38,2 \\
\hline 4. & Хороший уровень практической подготовки & 33,8 \\
\hline 5. & Профессионализм & 30,9 \\
\hline 6. & Хороший уровень теоретической подготовки & 29,4 \\
\hline 7. & Готовность выпускника к реагированию в нестандартной ситуации & 22,1 \\
\hline 8. & Производственная дисциплина & 14,7 \\
\hline 9. & Другое & 1,5 \\
\hline
\end{tabular}


При последующем внедрении данных опроса в учебный процесс администрации института следует обратить внимание на низкий результат, связанный с производственной дисциплиной выпускников: 14,7 \% респондентов не увидели достоинства в этом показателе. Среди основных недостатков респонденты отметили: недостаточный уровень практической подготовки $-35,7$ \%; отсутствие желания к саморазвитию и самообразованию - $25 \%$; низкая производственная дисциплина $21,4 \%$; отсутствие желания работать - 19,6 \% ответов (табл. 4).

Таблица 4

Недостатки выпускников ФКиС, отмеченные респондентами по результатам анкетирования (n=56) (выбор не более 3-х вариантов ответов)

\begin{tabular}{|c|l|c|}
\hline$№$ п/п & Недостатки & Результаты, \% \\
\hline 1. & Недостаточный уровень практической подготовки & 35,7 \\
\hline 2. & Отсутствие стремления к саморазвитию и самообразованию & 25,0 \\
\hline 3. & Плохая производственная дисциплина & 21,4 \\
\hline 4. & Нет желания работать & 19,6 \\
\hline 5. & Недостаточный уровень теоретической подготовки & 17,9 \\
\hline 6. & Низкий уровень общей профессиональной подготовки & 8,9 \\
\hline 7. & Несоответствие профессиональному стандарту & 3,6 \\
\hline 8. & Другое & 1,6 \\
\hline
\end{tabular}

Поиск оптимальной модели специалиста по физической культуре и спорту осуществляют многие вузы, особенно отраслевые, отнесенные по ведомственной принадлежности к Министерству спорта Российской Федерации. С учетом требований ФГОС 49.03.01 модель подготовки будущего выпускника по направлению «Физическая культура» для нужд Удмуртской Республики должна отвечать потребностям двух отраслей - физической культуры и спорта, а также образования, то есть носить комплексный характер и иметь универсальную направленность тренера-преподавателя.

Краткий обзор диссертационных исследований, посвященных проблеме моделирования будущих специалистов по физической культуре и спорту на уровне бакалавриата и магистратуры, приведенный ниже, позволяет утверждать, что таких исследований было проведено не так много, а по направлению «Физическая культура» - единицы. Все они, как правило, объединены единым подходом, основанным на формировании наиболее важных общекультурных, универсальных, общепрофессиональных, профессиональных и иных компетенций, в зависимости от перечня компетенций и требований ФГОС, действовавших на момент проведения исследования. Так, моделированием организационноуправленческих компетенций у студентов физкультурного вуза занималась И.Т. Шарыгина [20]. Формированием метапредметной компетентности магистрантов в условиях педагогической практики по физической культуре занималась И.Ю. Бурханова [2]. С.Н. Чернякова предложила модель формирования физкультурной компетентности с помощью элективной среды физического воспитания с информатизацией и дифференциацией учебного процесса, объединения учебной и внеучебной работы, модульного структурирования и спирального конструирования учебного материала, оценки достижений бакалавров с помощью рейтингов, а также практик в информационно-образовательной среде вуза. Было выявлено, что занятия по элективным видам спорта расширяют социальные контакты и взаимодействия бакалавров и стимулируют их физкультурно-спортивную активность [19]. Особая значимость в трудах К.Д. Волкова отдается специальным профессиональным компетенциям как наиболее важным условиям эффективности профессиональной деятельности в оздоровительном фитнесе [4].

Некоторые работы по подготовке бакалавров по другим направлениям подготовки также используют при создании модели выпускников подход, основанный на оптимальном сочетании компетенций, перечисленных во ФГОС и ПС. В исследовании Н.Б. Сэкулич была представлена модель формирования ИКТ-компетенций студентов в интерактивной ЭИОС университета, которая содержит требования, уровни сформированности, способы измерения ИКТ-компетенций [15]. В работе Т.А. Нестеровой говорится об эффективности создания ситуаций межкультурной коммуникации с применением интерактивных технологий для формирования межкультурной компетенции [8]. В.Н. Фефелова отмечает, что содержание управленческой компетентности обусловлено совокупностью управленческих функций, выполняемых в профессиональной деятельности [18]. В ходе научного исследования Т.Н. Михайловой была создана модель формирования общекультурной компетентности, в которой отмечается необходи- 
мость использования как традиционных, так и современных педагогических подходов, методов, форм и средств обучения [7].

Таким образом, исследования, проведенные по проблеме формирования моделей подготовки, квалифицированных бакалавров и магистров, основываются преимущественно на отборе компетенций, перечисленных во ФГОС и в наибольшей степени отвечающих требованиям практики и запросам работодателей.

На основании результатов, проведенных названными авторами исследований, и руководствуясь положением о том, что укрупненная модель выпускника по направлению 49.03 .01 «Физическая культура» [16] определяется практикой, а значит мнением работодателя, мы включили в анкету вопросы по оценке наиболее значимых для работодателя компетенций: универсальных (УК), общепрофессиональных (ОПК) и профессиональных (ПК). Перечень компетенций был заложен в матрицу вопросов анкеты с предложением работодателю оценить, в какой степени выпускники ИФКиС УдГУ должны обладать указанными выше компетенциями (предлагалось дать один ответ по каждой строке с оценкой от 1 до 5 баллов, при этом 5 - это наивысшая оценка). Аналогично были сформированы вопросы по всем трем блокам компетенций. В результате опроса работодателей получены результаты в виде суммы баллов. Все компетенции расположены в порядке убывания суммы баллов, по результатам чего сформирован рейтинг компетенций от работодателя. Более подробную информацию о результатах исследования по всем трем блокам компетенций можно получить из итоговых рейтинговых таблиц, имеющихся в распоряжении авторов.

Так, например, наиболее значимыми в оценке работодателей оказались следующие три универсальные компетенции (УК): УК-8 (характеризует способность создавать и поддерживать безопасные условия жизнедеятельности) - 299 баллов; УК-3 (характеризует способность осуществлять социальное взаимодействие, выполнять свою функцию в команде) - 299 баллов; УК-6 (способность рационально распределять свое время, создавать траекторию саморазвития) - 294 балла.

Наиболее значимыми в оценке работодателей оказались следующие три общепрофессиональные компетенции (ОПК): ОПК-1 (способность планировать занятия с учетом особенностей занимающихся, различного пола и возраста) - 307 баллов; ОПК-7 (соблюдает технику безопасности, профилактику травматизма, владеет способами оказания первой доврачебной помощи) - 305 баллов; ОПК-3 (умеет проводить физкультурно-спортивные мероприятия и занятия физической культурой) 304 балла.

Наиболее значимыми в оценке работодателей оказались следующие три профессиональные компетенции (ПК): ПК-1 (способность планировать и анализировать тренировочный процесс, а также соревновательную деятельность на этапах спортивной подготовки) - 297 баллов; ПК-2 (соблюдает принцип индивидуализации в спортивной подготовке - 291 балл; ПК-9 (умеет организовать физкультурно-оздоровительные мероприятия, организовывать досуг и активный отдых) - 290 баллов.

По результатам рейтинга компетенций сформирована укрупненная структура системы подготовки выпускника по направлению «Физическая культура», учитывающая:

1) требования ФГОС направления 49.03.01 «Физическая культура»;

2) требования профессиональных стандартов в области физической культуры и спорта;

3) рейтинг компетенций от работодателей;

4) практико-ориентированный подход к обучению в процессе организации практик и изучения спортивно-педагогических дисциплин.

Существует несколько подходов к практико-ориентированному обучению в системе высшего образования. Первый подход подразумевает погружение в профессиональную среду в процессе учебной, производственной и преддипломной практики (Вербицкий А.А., 2015) [3]. Второй подход определяет практико-ориентированное образование как систему профессионально-ориентированных технологий, технологий контекстного обучения (Петров И.В., 2010) [10]. Можно сделать вывод, что практико-ориентированное обучение возможно как для организации практик студентов, так и при изучении учебных дисциплин, особенно это характерно для спортивно-педагогических дисциплин и профильных практик по базовым видам спорта. Наиболее важными изменениями в образовательной программе, для повышения качества подготовки выпускников по физической культуре и спорту, с учетом практико-ориентированного обучения и постоянного взаимодействия с работодателем, респонденты выделили следующие технологии обучения (диаграмма в \% от общего числа полученных ответов представлена на рис. 8): 
О требованиях к подготовке кадров по физической культуре и спорту...

- Включение студентов-практикантов в производственный процесс - 58,5;

- Актуализация образовательных программ в соответствии с новыми технологиями - 49,2;

- Совмещение направлений подготовки (профилей) - 35.4.

Самыми востребованными качествами выпускников (помимо знания предметной области) были отмечены (в \% от общего числа ответов):

- Социальные навыки (деловое общение, работа в коллективе, владение социальными сетями) 70,6 ;

- Умение проявлять инициативу на работе - 69,1;

- Знания новейших технологий, включая информационные и цифровые технологии- 58,8 .

Стоит также отметить, что необходимость знания иностранного языка для работы в отрасли физической культуры и спорта высоко оценили только 5,9 \% работодателей. Очевидно, это объясняется закрытостью региона для иностранных специалистов и спортсменов, отсутствием международных соревнований на территории Удмуртии. Работодателям было предложено в свободной форме дать предложения по улучшению в будущем подготовки выпускников в УдГУ. Обобщив ответы, можно выделить следующие предложения:

- образовательный процесс максимально приблизить к местам и условиям труда, выделять больше времени на практики в спортивных школах, обучению ведения и заполнения необходимой документации в работе;

- больше практических знаний в соответствии с выбранным видом спорта, профессиональный подход к выбранному виду спорта, для дальнейшего его применения в работе в организации;

- привитие интереса и любови к работе по выбранной профессии;

- повышение общего качества подготовки специалистов, повышение качества знаний в области теории и методики физической культуры и спорта;

- умение работать в условиях недостаточного финансирования, отсутствия необходимого оборудования, инвентаря и пр.;

- способность выпускника проявлять и применять свои знания, умения и навыки в соответствии с новыми требованиями;

- развитие социальных навыков (деловое общение), коммуникаций, развитие навыков в проектной деятельности, разноплановая инициатива.
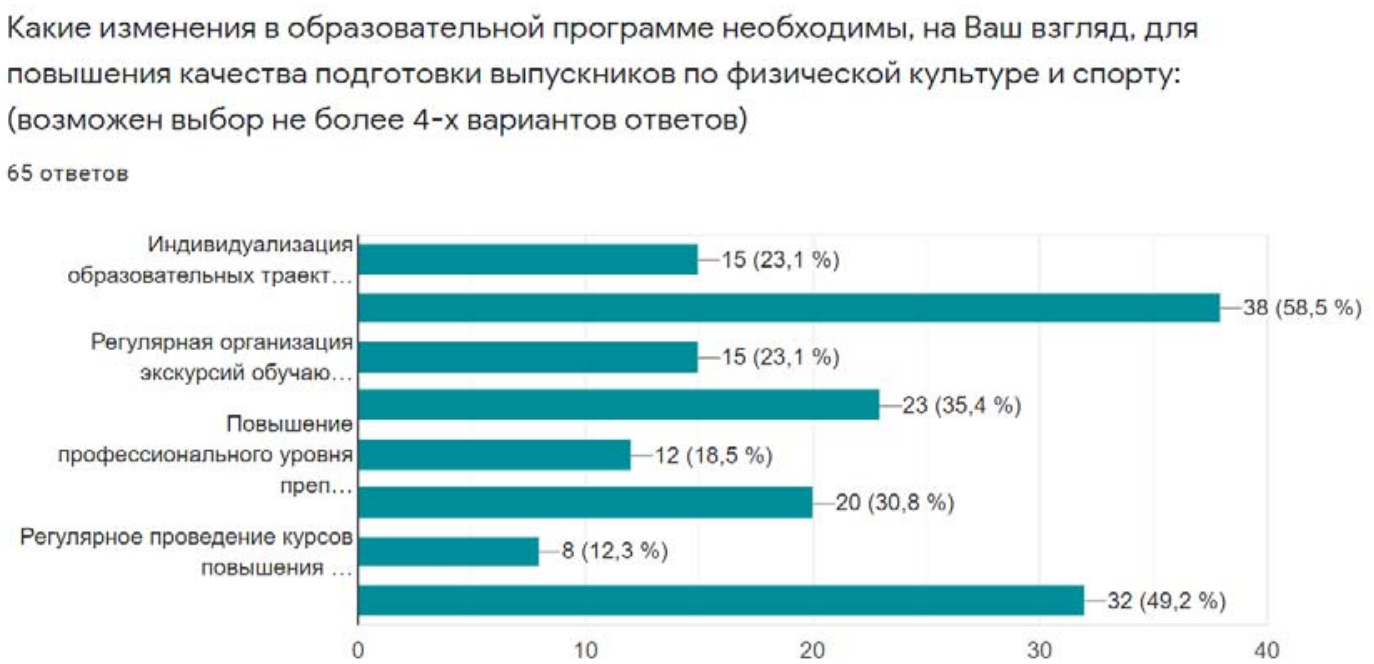

Рис. 8. Предложения работодателей по совершенствованию образовательной программы по направлению Физическая культура

Форматы работы со икольниками-абитуриентами, обеспечивающие их профессиональную ориентацию, привлечение и закрепление талантливых выпускников икол с ориентацией на обучение по направлению "Физическая культура" и работу в отраслях физической культуры и спорта, образования, остаются прежними, проверенными опытом многолетней работы за 70 лет существования Института физической культуры и спорта, а именно: 
1) проведение совместно с Министерством образования и науки УР, образовательными организациями на базе УдГУ финальных муниципальных (Ижевск) и региональных этапов предметных олимпиад по физической культуре;

2) проведение агитационных мероприятий с потенциальными абитуриентами во время спортивных соревнований среди школьников в соответствии с единым планом физкультурных и спортивных мероприятий УР, муниципальных образований УР;

3) проведение профориентационной работы на соревнованиях среди школьников, тренеров, судей, руководителей на семинарах, курсах повышения квалификации и переподготовки;

4) реализация имиджевых для института ФКиС проектов «Бежим с УдГУ» и «УдГУ - территория ГТО» и др.

Форматы, обеспечивающие трудоустройство выпускников по направлению Физическая культура и их закрепление в организациях физической культуры, спорта и образования Удмртской Республики. За последние пять лет только 20 \% опрошенных организаций не приняли на работу выпускников ИФКиС УдГУ. 68 \% организаций приняло в свой штат до 5 выпускников, остальные же организации приняли от 5 до 15 наших выпускников. Также стоит отметить, что о своем желании принимать на работу выпускников института изъявило 88 \% опрошенных, а о желании развивать деловые связи с институтом положительно ответило 98 \%. Наибольший интерес в сотрудничестве у опрошенных организаций вызвали следующие форматы, в \% от числа респондентов (рис. 9):

- заключение соглашений о прохождении практики студентов - 76,1;

- проведение совместных мероприятий - 50,7;

- участие в учебной, научной и воспитательной деятельности института (проведение открытых мастер-классов, тематических лекций, практических занятий, научных мероприятиях и др.) - 38.8;

- организация стажировок обучающихся - 37,3;

- участие в профориентационных мероприятиях института $-25,4$.

Если Вы желаете развивать деловые связи и сотрудничество с ИФКиС УдГУ, то в каких формах? (возможен выбор не более 3-х вариантов ответов)

67 ответов

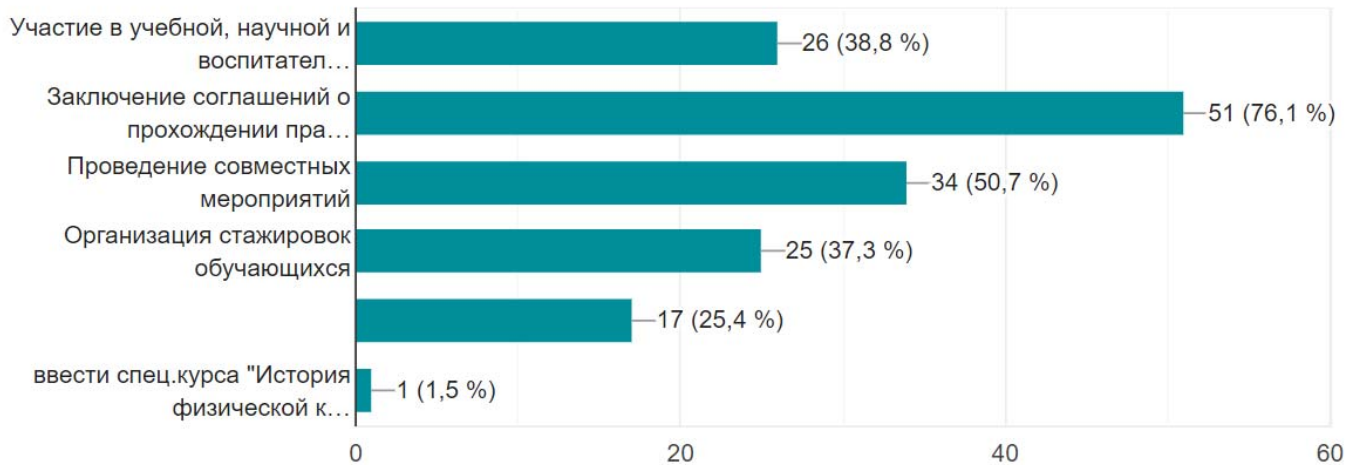

Рис. 9. Предложения работодателей по трудоустройству выпускников по направлению «Физическая культура»

По состоянию на 2020 г., а также на ближайшую перспективу с 2021 по 2023 г. респонденты отметили, что нуждаются в следующем количестве кадров по физической культуре и спорту (табл. 5).

Форматы непрерывного образования, обеспечивающие соответствие компетенций сотрудников организаций актуальным потребностям рынка труда. На вопрос о необходимости дополнительного профессионального образовании также были получены ответы респондентов, которые можно разбить на три группы: дополнительное образование тренерских кадров, педагогов, специалистов адаптивной физической культуры.

Дополнительное профессиональное образование тренерских кадров:

- курсы повышения квалификации по видам спорта: игровые виды спорта, легкая атлетика, лыжные гонки, морское многоборье, полиатлон, парусный спорт, спортивная гимнастика, велосипедный спорт. 
О требованиях к подготовке кадров по физической культуре и спорту...

- курсы повышения квалификации по психологической подготовке спортсменов, психологическим портретам людей и как с ними находить общий язык в тренировочном процессе, психологический практикум, психологии работы с детьми и подростками;

- курсы повышения квалификации по подготовке и методам подготовки высококвалифицированных спортсменов, планированию восстановительных программ (приведение в норму после длительных нагрузок, правильное сочетание нагрузок и отдыха); логиями;

- курсы повышения квалификации по менеджменту в спорте, владению современными техно-

- курсы повышения квалификации по судейству;

- курсы повышения квалификации для тренеров-инструкторов;

- курсы переподготовки по программе «Физическая культура и спорт».

Дополнительное профессиональное образование специалистов по адаптивной физической культуре $(A \Phi K)$ :

- курсы переподготовки по адаптивным образовательным программам;

- курсы повышения квалификации по современной спортивной медицине;

- курсы переподготовки по адаптивной физической культуре в дистанционном формате;

Дополнительное образование педагогических кадров: культуры;

- курсы повышения квалификации и переподготовки по ФГОС и ПС для учителей физической

• курсы повышения квалификации по методическому обеспечению.

Таблица 5

Востребованность кадров по физической культуре и спорту в УР в зависимости от профиля выпускника

\begin{tabular}{|c|c|c|c|}
\hline $\begin{array}{l}\text { № } \\
\Pi / \Pi\end{array}$ & Профиль выпускника & $\begin{array}{l}\text { В текущем } \\
2020 \text { году }\end{array}$ & $\begin{array}{l}\text { В будущем } \\
\text { периоде, } \\
2021-2023 г г .\end{array}$ \\
\hline 1 & Тренер & 18 & 37 \\
\hline 2 & Инструктор-методист & 10 & 13 \\
\hline 3 & Тренер по адаптивной физической культуре & 2 & 8 \\
\hline 4 & Педагог по физической культуре & 5 & 6 \\
\hline 5 & $\begin{array}{l}\text { Руководитель организации (подразделения организации), осуществ- } \\
\text { ляющей деятельность в области физической культуры и спорта }\end{array}$ & 1 & 5 \\
\hline 6 & $\begin{array}{l}\text { Инструктор-методист по адаптивной физической культуре } \\
\text { и адаптивному спорту }\end{array}$ & 0 & 4 \\
\hline 7 & $\begin{array}{l}\text { Специалист по обслуживанию и ремонту спортивного инвентаря } \\
\text { и оборудования }\end{array}$ & 0 & 3 \\
\hline 8 & Специалист по антидопинговому обеспечению & 1 & 1 \\
\hline 9 & Специалист по продвижению фитнес-услуг & 4 & 5 \\
\hline \multirow[t]{2}{*}{10} & $\begin{array}{l}\text { Специалист по инструкторской и методической работе в области } \\
\text { физической культуры и спорта }\end{array}$ & 5 & 8 \\
\hline & Итого: & 55 & 90 \\
\hline
\end{tabular}

\section{Выводы}

1. В настоящее время существуют значительные проблемы в сфере кадрового обеспечения отрасли физической культуры и спорта Удмуртской Республики:

a) с 2015 по 2019 год наблюдается снижение доли специалистов в возрасте до 30 лет на 10,2\% и увеличение лиц старше 60 лет на 43,7 \%. То есть довольно быстрыми темпами происходит старение тренеров по спорту ввиду отсутствия инструментов привлечения в отрасль молодых специалистов;

б) в структуре работающих в отрасли специалистов по уровню образования (СПО и ВО) за последние 5 лет в динамике просматривается явная тенденция увеличения специалистов, имеющих среднее профессиональное образование (с 784 до 920 человек), на 17,4 \% и уменьшения числа спе- 
циалистов с высшим образование - с 3011 до 2800 человек $(-7,1$ \%). Кризисное состояние отрасли отражает также и количество вакансий тренеров, которое держится на протяжении двух последних лет на уровне 133.

2. Вместе с тем система спортивной подготовки, реализуемая на основе ФССП, охватывает все большее число физкультурно-спортивных организаций, передаваемых из системы образования в систему управления спортом. Так, только за последние годы сформирована сеть из более чем 90 спортивных организаций, в которых работает более 4 тыс. специалистов - тренеров, административных работников, методистов; требуется постоянное кадрового обновления, профессиональной подготовки и переподготовки в рамках профильного образования и требований профессиональных стандартов.

3. Несмотря на то что рынок физкультурного образования в Удмуртской Республике практически монопольно принадлежит Удмуртскому государственному университету, выпускники которого составили 64,7 \% работающих в отрасли специалистов, развития физкультурного образования в республике в перспективе не предполагается: по прогнозу Министерства социальной политики и труда УР, специалистов по физической культуре и спорту в Удмуртии на ближайшие 5 лет (к 2026 г.) в разрезе видов экономической деятельности дополнительно потребуется 566 чел., что к 2020 г. составляет прирост всего 41 чел., или 7,8 \%. Прогноз потребности рынка труда Удмуртской Республики в кадрах в разрезе укрупненных групп специальностей по всем уровням образования на 2020-2026 годы еще более неутешительный. Так, по укрупненной группе специальностей 49.00.00 «Физическая культура и спорт» в УР, по прогнозу министерства, будут востребованы дополнительно к имеющимся всего 73 специалиста, то есть роста в сопоставлении к 2020 году практически не планируется. Однако, по данным опроса работодателей, потребность на 2021 год - 55 человек, на период до 2023 года - 90;

4. С учетом небольшого числа выделяемых Удмуртскому университету бюджетных мест по направлению «Физическая культура», наличия профильных спортивных вузов в соседних регионах, создающих объективную конкуренцию Институту физкультуры УдГУ, последний должен работать с выпускниками спортивных и общеобразовательных школ, тренерами, спортсменами на опережение, предоставляя для них еще в период обучения в школе максимально подробную информацию об условиях обучения, образовательных программах, работодателях, делая акцент на практико-ориентированное обучение и максимальное взаимодействие с организациями-работодателями в период учебы и прохождения практик. Важным конкурентным преимуществом для регионального вуза в подготовке кадров становится учет конкретных требований и условий к региональным особенностям развития отрасли и организаций-работодателей к овладению выпускниками наиболее востребованными компетенциями, предусмотренными ФГОС ВО в аспекте требований профессиональных стандартов (ПС) и ФССП в области физической культуры и спорта.

5. Опыт, накопленный ИФКиС УдГУ за 70 лет подготовки выпускников, отражен в результатах опроса, в котором 88 \% опрошенных представителей работодателей отметили высокий уровень теоретической подготовленности выпускников Института физической культуры и спорта УдГУ, в том числе: 23,5 \% - удовлетворены полностью, 51,5 \% - в основном, 13,2 \% - частично. Удовлетворенность работодателей практической подготовленностью выпускников ИФКиС по направлению «Физическая культура» еще выше: 89,9 \% опрошенных представителей работодателей отметили высокий уровень подготовленности к практической работе. При последующем внедрении данных опроса в учебный процесс администрации института следует обратить внимание на низкий результат, связанный с производственной дисциплиной выпускников: 14,7 \% респондентов не увидели достоинства в этом показателе. Среди основных недостатков респонденты отметили: недостаточный уровень практической подготовки - 35,7 \%; отсутствие желания к саморазвитию и самообразованию - 25 \%; низкая производственная дисциплина $-21,4$ \%; отсутствие желания работать - 19,6 \% ответов.

6. С учетом требований ФГОС 49.03.01 «Физическая культура» модель подготовки будущего выпускника по направлению «Физическая культура» для нужд Удмуртской Республики, по данным научных и методических работ, должна отвечать потребностям двух отраслей - физической культуры и спорта, а также образования, то есть носить комплексный характер и иметь универсальную направленность тренера-преподавателя. Все они, как правило, объединены единым подходом, основанным на формировании наиболее важных общекультурных, общепрофессиональных, универсальных, профессиональных и иных компетенций, в зависимости от перечня компетенций и требований ФГОС, действовавших на момент проведения исследования. По результатам рейтинга компетенций сформирована укрупненная модель выпускника по направлению «Физическая культура», учитывающая: тре- 
бования ФГОС направления 49.03.01 «Физическая культура»; требования профессиональных стандартов в области физической культуры и спорта; рейтинг компетенций от работодателей; практикоориентированный подход к обучению в процессе организации практик и изучения спортивнопедагогических дисциплин.

7. По итогам работы сформирован перечень наиболее эффективных форматов в работе с потребителями образовательных услуг по направлению «Физическая культура», в том числе: а) форматы работы со школьниками-абитуриентами, обеспечивающие их профессиональную ориентацию, привлечение и закрепление талантливых выпускников школ в Удмуртском университете с ориентацией на отрасль физической культуры и спорта и образования региона; б) форматы, обеспечивающие трудоустройство выпускников и их закрепление в физкультурно-спортивных организациях и организациях образования Удмуртской Республики.

\section{СПИСОК ЛИТЕРАТУРЫ}

1. Анкета работодателя в области физической культуры и спорта [Электронный ресурс] // Google Forms. URL: https://docs.google.com/forms/d/1k4AuUE59nJYeo-ASuFi9wKiQSq9G16BTbf2OYCbOfYY/edit?ts=5ecbfec5 (дата обращения: 01.06.2020).

2. Бурханова И.Ю. Формирование метапредметной компетентности магистрантов в условиях практики: дис. ... канд. пед. наук: 13.00.08 / Рос. гос. ун-т физ. культуры, спорта, молодежи и туризма. М, 2018. 178 с.

3. Вербицкий А А. Проблемы проектно-контекстной подготовки специалиста // Высшее образование сегодня. 2015. № 4. С. 2-8.

4. Волков К.Д. Формирование у будущих специалистов по физической культуре и спорту специальных профессиональных компетенций для работы в оздоровительном фитнесе: автореф. дис. ... канд. пед. наук: 13.00.08. M., 2009. 24 c.

5. Количество мест для приема на 2020/2021 учебный год по программам бакалавриата в ПГАФКСиT. URL: https://www.sportacadem.ru/files/abiturientu/bakalavriat_obwee.pdf (дата обращения: 24.07.2020).

6. Количество мест для приема на обучение по различным условиям поступления (с указанием особой квоты, без указания целевой квоты, по договорам оказания платных образовательных услуг) в ЧГИФиC. URL: http://www.chifk.ru/files/02019_priem_bak kolvo_mest priema.pdf (дата обращения: 24.07.2020).

7. Михайлова Т.Н. Формирование общекультурной компетентности курсантов вузов МВД России в процессе их самоактуализации: дис. ... канд. пед. наук: 13.00.01 / Бурят. гос. ун-т. Улан-Удэ, 2018. 201 с.

8. Нестерова Т.А. Формирование межкультурной компетенции в условиях профессиональной социализации студентов педагогического колледжа: дис. ... канд. пед. наук: 13.00.01 / Бурят. гос. ун-т. Чита, 2018. 208 с.

9. Отчет Министерства спорта Российской Федерации о результатах анализа состояния и перспектив развития системы образования за 2018 год. URL: https://www.minsport.gov.ru/activities/science/obrazovanie/ (дата обращения: 24.07.2020).

10. Петрова И.В. Формирование профессиональных компетенций у студентов вузов в ходе практикоориентированного обучения: на примере строительных специальностей: автореф. дис. ... канд. пед. наук. Ульяновск, 2010. 30 с.

11. Показатели развития Физической культуры и спорта 2019. URL: https://www.minsport.gov.ru/sport/physicalculture/statisticheskaya-inf/ (дата обращения: 24.07.2020).

12. Портал Федеральных государственных образовательных стандартов высшего образования. URL: http://fgosvo.ru/ fgosvo/151/150/24/99 (дата обращения: 24.07.2020).

13. Прогноз потребности рынка труда Удмуртской Республики в квалифицированных кадрах с учетом социально-экономического развития Удмуртской Республики на 2020 - 2026 годы [Электронный ресурс] // Министерство социальной политики и труда Удмуртской Республики. URL: http://минсоцполитики18.pф/labor/ labor-market/forecasts/4777/ (дата обращения: 01.06.2020).

14. Сведения о количестве мест для приема на обучение в рамках контрольных цифр по различным условиям поступления с указанием особой и целевой квоты. URL: https://udsu.ru/admissions/2020/svedeniya-o-kolichestvemest-2020 (дата обращения: 24.07.2020).

15. Сэкулич Н.Б. Интерактивная электронная информационно-образовательная среда университета как средство формирования ИКТ-компетенций студентов: дис. ... канд. пед. наук: 13.00.01 / Бурят. гос. ун-т. Улан-Удэ, 2018. 194 с.

16. Федеральный государственный образовательный стандарт высшего образования - бакалавриат по направлению подготовки [Электронный ресурс] // Портал Федеральных государственных образовательных стандартов высшего образования. URL: http://fgosvo.ru/uploadfiles/FGOS\%20VO\%203++/ Bak/490301_B_3_ 30102017.pdf (дата обращения: 01.06.2020). 
17. Федеральный закон от 04.12.2007 № 329-Ф3 (ред. от 02.08.2019) «О физической культуре и спорте в Российской Федерации». URL: http://www.consultant.ru/document/cons_doc_LAW_73038/7b787f81ddf150df9c8be 93658708c412e34fdbe (дата обращения: 01.06.2020).

18. Фефелова В.Н. Формирование управленческой компетентности специалиста по рекреации и туризму: дис. ... канд. пед. наук: 13.00.08 / Рос. гос. ун-т физ. культуры, спорта и туризма. М, 2010. 187 с.

19. Чернякова С.Н. Формирование физкультурной компетентности бакалавров в информационнообразовательной среде вуза: дис. ... канд. пед. наук: 13.00.04 / Тюмен. гос. ун-т. Тюмень, 2015. 261 с.

20. Шарыгина И.Т. Формирование организационно-управленческих компетенций у студентов физкультурного вуза [Электронный ресурс] // Военный институт физической культуры. Министерство обороны Российской Федерации URL: https://vifk.mil.ru/upload/site49/document_file/PCX9VMly9N.pdf (дата обращения: 01.06.2020).

Поступила в редакцию 28.08.2020

Новокрещенов Владимир Васильевич, доктор педагогических наук, профессор, профессор кафедры теории и методики физической культуры, гимнастики и безопасности жизнедеятельности E-mail: sportm@mail.ru Алабужев Сергей Александрович, мастер спорта России E-mail: sergh.al@yandex.ru ФГБОУ ВО «Удмуртский государственный университет» 426034, Россия, г. Ижевск, ул. Университетская, 1

\section{V.V. Novokreshchenov, S.A. Alabuzhev \\ TRAINING REQUIREMENTS FOR PERSONNEL WORKING IN THE AREA OF PHYSICAL CULTURE AND SPORTS IN THE UDMURT REPUBLIC}

DOI: $10.35634 / 2412-9550-2020-30-4-407-420$

The situation with the staffing of the industry "Physical culture and sports" in the Udmurt Republic according to the state statistical reporting for the last 5 years and, in this regard, the process of personnel training in the framework of the direction 49.00.00 "Physical culture and sports" in the Udmurt Republic as a whole and in the Udmurt State University, in particular, is considered. Using the platform of the Google Forms resource, the authors conducted a survey of 80 organizations-employers in order to form a system at the university that provides training of qualified personnel in physical culture and sports. According to employers, in the interpretation of the authors, the system should include: fulfillment of the requirements of the Federal State Educational Standard of the direction 49.03.01 "Physical culture"; requirements of professional standards in the field of physical culture and sports; rating of competencies from employers; practice-oriented approach to teaching in the process of organizing practices and studying sports and pedagogical disciplines. In addition, the authors have systematized and generalized proposals for the formatting of work with applicants and graduates in order to retain personnel in the physical culture and sports organizations of the republic.

Keywords: educational system, personnel training, physical culture and sports, employers' requirements, federal standard, professional standard, graduates' competencies.

Received 28.08.2020

Novokreshchenov V.V., Doctor of Pedagogy, Professor,

Professor at Department of Theory and Methods of Physical Culture, Gymnastics and Life Safety

E-mail: sportm@mail.ru

Alabuzhev S.A., Master of Sports of Russia

E-mail: sergh.al@yandex.ru

Udmurt State University

Universitetskaya st., 1, Izhevsk, Russia, 426034 